\title{
Exchange Rate Regimes and Revenue Performance in Sub-Saharan Africa*
}

\author{
C.S.Adam, D.L.Bevan and G.Chambas ${ }^{\dagger}$
}

January 2000

\begin{abstract}
It has been argued that the institutions of the CFA Franc zone may have reduced inflation but that they also induced misalignment of the real exchange rate and that this is the explanation for their dismal revenue performance. This paper uses a panel of 22 countries in sub-Saharan Africa to estimate revenue performance over the period from 1980 to 1996. It finds that the poor cumulative relative revenue performance of the franc zone countries is mainly attributable to differences in environmental and structural factors, and to their different responses to changes in the equilibrium real exchange rate, but that the misalignment of the real exchange rate also played a part.
\end{abstract}

\section{Introduction}

During the 1980s and early 1990s the countries of the CFA Franc zone experienced a steady decline in the ratio of tax to GDP, from almost 15 percent of GDP in the early 1980s to only $11.5 \%$ in the early 1990s. By contrast, over the same period the tax yield in countries outside the zone remained remarkably stable at around $15.5 \%$. Following the devaluation of the CFA Franc in January 1994, the decline in the tax ratio halted and there is evidence of a slight recovery by 1996. This pattern of relative decline in the CFA zone is repeated for each of the major components of total tax revenue namely income taxes, domestic indirect taxes and taxes on international trade ( See Figure 1 and Table 1). ${ }^{1}$

**** Table 1 here $* * * *$

${ }^{*}$ This paper draws on earlier work by the authors (Adam et al, 1998) examining revenue productivity over the 1980s. We are grateful to Ludivico Carraro for valuable research assistance and to Steve O'Connell and an anonymous referee for comments on an earlier version of this paper.

${ }^{\dagger}$ Department of Economics, University of Oxford (Adam and Bevan) CERDI, Universitè d'Auvergne (Chambas).

${ }^{1}$ Throughout this paper we are basing our inference on a sample of countries in SSA, not on the population. This partly reflects data availability but we also intentionally exclude countries whose tax base is dominated by natural resources - notably the oil-producing countries. A complete description of the data and sample is provided in the Data Appendix. 


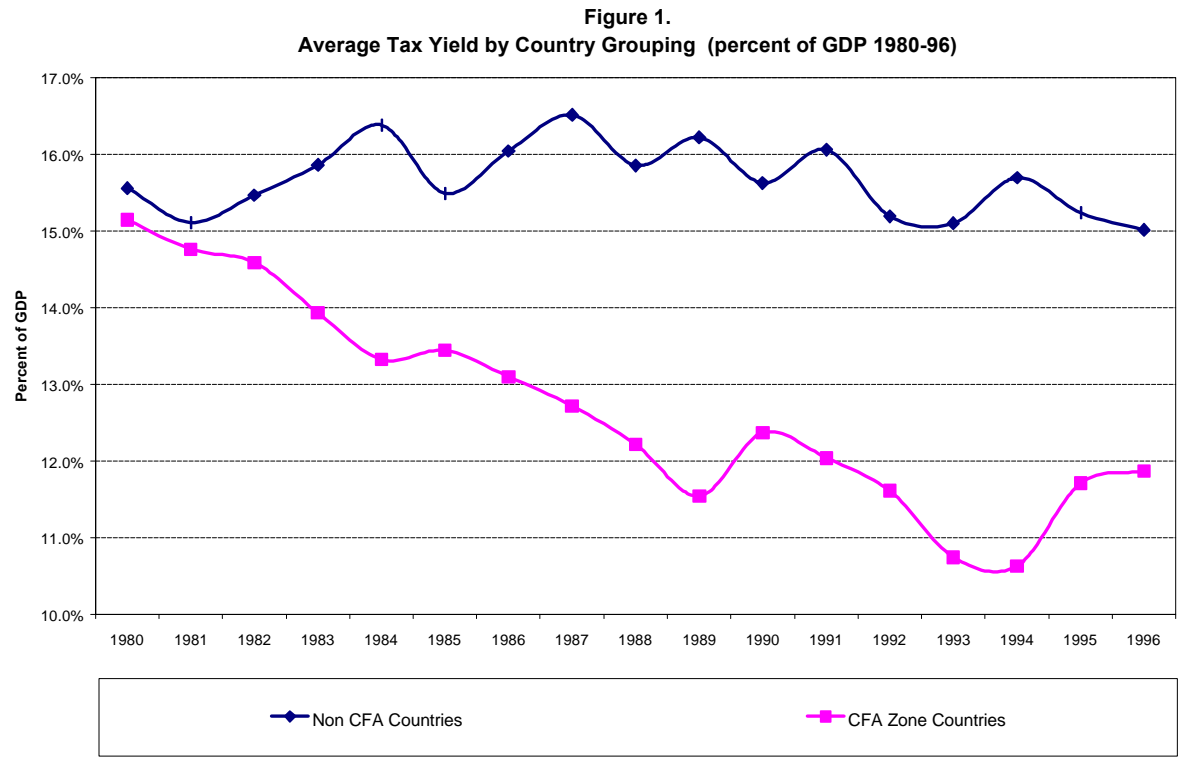

A natural question is whether these differences can be explained solely in terms of a different evolution of the determinants of revenue productivity or whether the two groups of countries differ in a more fundamental sense. A substantial literature has explored how the institutional characteristics of the zone may have contributed to a distinctive macroeconomic response to external events. This literature argues that the mechanism guaranteeing the convertibility of the CFA Franc, the overdraft facility provided by the Banque de France, relieves the domestic economy of the obligation to adjust to external disequilibria, at least in the short to medium term. It has been suggested that whilst this structure successfully delivered low inflation and high growth in the early 1980s, the inflexibility it imparted to the domestic price system retarded adjustment to deteriorating external circumstances in the late 1980s and 1990s. Thus domestic price inflexibility contributed to the emergence of large and persistent misalignment of the real exchange rate relative to its equilibrium level in the CFA zone, long after other economies of sub-Saharan Africa had established more flexible exchange rate arrangements (see for example de Melo and Devarajan, 1991). Nashashibi and Bazzoni (1994) develop this argument, conjecturing that:

"a major factor in the deterioration of fiscal performance in the fixed-rate [i.e. CFA] countries during the second half of the 1980s was that the real exchange rate increasingly diverged from its equilibrium path. Conversely, the variable rate countries were able to improve their fiscal performance because their real exchange rate was converging towards its equilibrium path." [pp 118-19].

In this paper we subject this conjecture to econometric scrutiny by conducting an empirical investigation of revenue performance in sub-Saharan Africa for the period from 1980-1996. The paper follows in the tradition of Heller (1975) and Leuthold (1996) and corresponds quite closely to a recent paper by 
Ghura (1998) which examines the impact of macroeconomic policy choices and of measures of corruption on total revenue productivity for the period 198596. Ghura's work partially supports the Nashashibi and Bazzoni view by finding significant differences between CFA and non-CFA countries - reflected in a significant group-specific intercept shift - but she finds no significant role for changes in the real exchange rate or its fundamentals. Although we use a similar data set we are able to examine more closely the role of the real exchange rate by adopting a less restrictive econometric specification and by disaggregating total tax revenue into its principal components which, from a theoretical perspective, may be expected to respond differently to the real exchange rate and its determinants. ${ }^{2}$

This approach allows us to address two key issues not addressed in earlier work. First, since our sample spans the period from 1980 to 1996 we can explicitly test a time-invariant common model of revenue performance against an alternative model in which the transmission from external and policy factors to revenue performance differs between the two regimes and over time. Of particular interest, of course, is whether the CFA devaluation of 1994 has altered revenue productivity in the zone. Second, by estimating an explicit model for the evolution of the equilibrium real exchange rate, we can distinguish between the response of tax revenue to the misalignment of the real exchange rate as opposed to equilibrium movements in it.

Our empirical strategy is not without limitations. As with most studies of revenue performance, we lack reliable information on the evolving structure of the tax system, hence our analysis is restricted to crude tax yields. However, while it is not possible directly to control for changes in the tax regime, panel data methods do allow us to control for unobservable time-invariant countryspecific characteristics determining revenue performance, which will include amongst other features the general stance of the tax system (see also Leuthold, 1996). A second limitation is that we are unable to distinguish between the effects of the different institutional elements of the CFA zone, for example the effect of the fixed nominal exchange rate and the effect of guaranteed convertibility. At best, therefore, we are able to comment on the net effect on revenue productivity of the CFA institutions as a whole rather than directly on the role of the nominal exchange rate regime itself (although our focus on the real exchange rate and the inflation rate means that we do control for some of the implications of the regime).

To set the stage, we start with a brief presentation of the data including some preliminary estimates of the buoyancy of the tax system. This is followed in Section 3 with a simple model of revenue performance which identifies the role of the real exchange rate and its determinants (the so-called fundamentals). A complication for the empirical analysis is that these 'fundamentals' may have a direct impact on revenue productivity as well as an indirect one via their effect on the exchange rate. The model thus provides a framework within which

\footnotetext{
${ }^{2}$ In contrast to Ghura's 39 country unbalanced panel, our analysis is limited to the balanced panel investigated by Nashashibi and Bazzoni although the time dimension is extended to cover the period from 1980-96. We examine the three principal components of tax revenue only but exclude non-tax revenue. As Table 1 shows, while non-tax revenue in the non-CFA countries has been realtively stable over time, there has been a sharp collapse in non-tax revenue in the CFA zone. This reflects in the main factors beyond the scope of this paper such as the the reform of the caisse de stabilisation and other marketing boards which have played a significant role in public sector operations in the zone.
} 
these effects can be disentangled in the empirical application. Section 4 presents the results from the estimated revenue and real exchange rate equations while Section 5 concludes with a summary of the results.

\section{Preliminary evidence}

The countries in our sample share a broadly common structure of production where agriculture accounts for around 35 percent of GDP, industry and mining for around 20 percent, and have been subject to similar external terms of trade developments, especially during the 1980s (see Table 2 and Figure 2). But here the similarities end. The reaction to these broadly similar external conditions differed in interesting ways and, it would appear, with very different consequences. Although the real exchange rate depreciated by the same amount over the period as a whole, the evolution was very different. Whereas the average real exchange rate for the non-CFA countries depreciated steadily up until 1993 (and then appreciated slightly) that for the CFA zone remained relatively overvalued until the devaluation of the CFA franc in January $1994 .^{3}$ A similar pattern is reflected in the evolution of the aid flow: both groups enjoyed an increase in net aid inflows as a percent of GDP. However, since these data are expressed in domestic currency terms, they also reflect movements in the real exchange rate, as can be seen from Figure 2. In foreign currency terms the net aid flow to both groups of country was much more stable over time. Another related difference is that whereas over time the non-CFA economies became more open to trade, the opposite was happening in the CFA zone, with this again being reversed after the devaluation in $1994 .{ }^{4}$ The final feature of the data is a direct reflection of the nominal exchange rate regime: with the exception of the jump in domestic prices around the devaluation, the CFA countries have enjoyed consistently lower inflation than the non-CFA countries.

The most striking difference, however, is in the evolution of average real per capita income. Despite virtually identical population growth over the period, per capita incomes in the CFA zone declined steadily throughout the period until 1993, both absolutely and relative to the non-CFA countries where, by contrast per capita incomes have risen steadily over the same period.

**** Table 2 here $* * * *$

\footnotetext{
${ }^{3}$ Note that the real exchange index in Figure 2 is normalized so that $1980=100$. By contrast the data in Table 2 are normalized to 100 over the period 1980-85.

${ }^{4}$ As with the measure of aid flows, movements in this measure of openness (i.e. the trade share in GDP) also reflect the consequences of real exchange rate changes which revalue the tradable relative to non-tradable components of GDP.
} 
Figure 2: Macroeconomic Variables

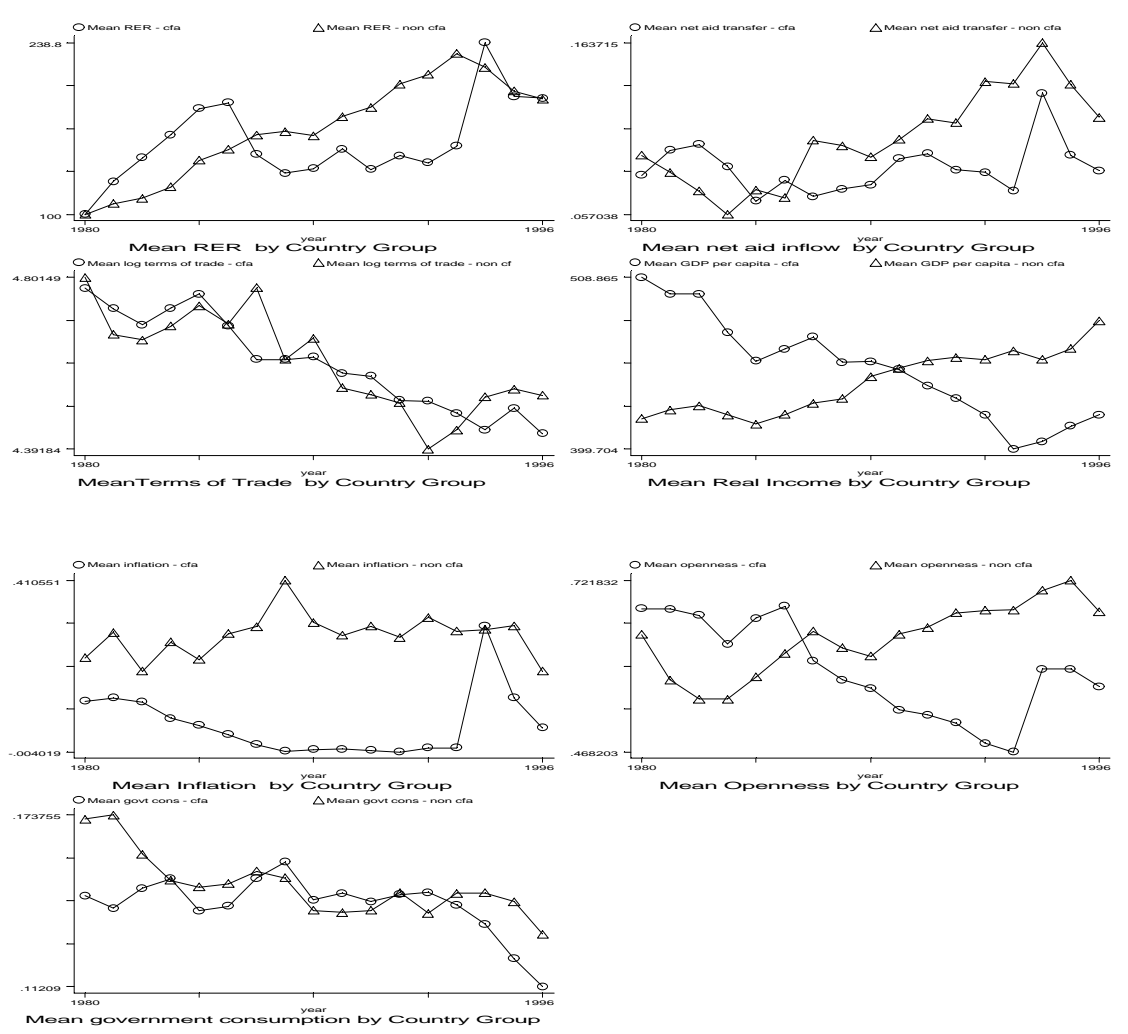

\subsection{Tax buoyancy}

To complete our discussion of the data we report preliminary estimates of the buoyancy of the tax structure across the two country groupings. The buoyancy estimates are estimated from the following fixed-effects model

$$
\left(\frac{t}{y}\right)_{i t}=\alpha+\beta_{1} \ln y_{i t}+\beta_{2}\left(\ln y_{i t} * c f a\right)+s_{t}+\varepsilon_{i t}
$$

where $(t / y)$ denotes the tax yield, $y$ denotes per capita GDP in constant prices, and $c f a$ is a dummy variable taking the value of one if the country is a member of the CFA zone. We also add a vector of time dummy variables, denoted $s_{t}$, to control for common time-varying effects. The error term follows the standard one-way error specification

$$
\varepsilon_{i t}=\mu_{i}+\nu_{i t}
$$

providing the opportunity to control for country-specific effects. Table 3 reports the results of estimating equation (1) for total taxes and each of the tax components (where, for convenience, we have suppressed the coefficients on the time dummy variables). 
Table 3: Estimated Tax Buoyancy

\begin{tabular}{|c|c|c|c|c|}
\hline OLS (F & $\begin{array}{l}\text { ed Effects) } \\
\text { total tax }\end{array}$ & $\begin{array}{l}\text { Estimation. } \\
\text { income tax }\end{array}$ & $\begin{array}{l}\text { Sample: } 1980 \\
\text { indirect tax }\end{array}$ & $\begin{array}{l}1996 \\
\text { trade tax }\end{array}$ \\
\hline \multirow[t]{2}{*}{ constant } & -0.327 & -0.164 & -0.195 & 0.035 \\
\hline & {$[4.88]$} & {$[5.60]$} & {$[4.43]$} & {$[0.82]$} \\
\hline \multirow[t]{2}{*}{$\ln y$} & 0.037 & 0.027 & 0.041 & -0.032 \\
\hline & {$[3.32]$} & {$[5.63]$} & {$[5.62]$} & {$[4.59]$} \\
\hline \multirow[t]{2}{*}{$\operatorname{lny}{ }^{*} \mathrm{cfa}$} & 0.117 & 0.024 & 0.002 & 0.093 \\
\hline & {$[4.77]$} & [2.268] & {$[0.15]$} & {$[5.98]$} \\
\hline Adjusted-R $^{2}$ & 0.178 & 0.147 & 0.114 & 0.236 \\
\hline F-pooling & 71.81 & 130.53 & 32.73 & 34.86 \\
\hline Prob & {$[0.000]$} & {$[0.000]$} & {$[0.000]$} & {$[0.000]$} \\
\hline $\mathbf{n}$ & 373 & 373 & 373 & 373 \\
\hline
\end{tabular}

Note: $\mathrm{R}^{2}$ denotes within-group coefficient of determination.

t-statistics in parentheses. F-pooling denotes $\mathrm{F}$ test of country-specific effects.

Note that since the dependent variable is a tax share the coefficient on $\ln y_{i t}$ measures the (percentage) deviation from a unit tax buoyancy. These estimates point to two important features of the data. First, for the non-CFA countries, rising real per capita GDP leads to a rising total tax ratio but the composition of total tax is skewed away from trade taxes towards domestic income and indirect taxes. Second, with the exception of domestic indirect taxes, the tax system in the CFA zone appears to be significantly more buoyant than that in countries outside the zone. This implies a gearing-up of the revenue consequences of growth differentials between the groups of countries. Hence the decline in per capita GDP over the period in the CFA zone (both absolutely and relative to the non-CFA countries) seen in Figure 2 translates into the rapid decline in total revenue in the CFA zone and the widening differential between zone and non-zone countries up until around 1993. It is important to note, however, that the differential in these crude buoyancy measures implies that revenue will recover more rapidly in the CFA than elsewhere as real per capita incomes rise. However, the simple buoyancy equations explain a relatively small proportion of the variation in revenue productivity, as indicated by the $\mathrm{R}^{2}$ indicators. To address this problem, and to unravel these crude buoyancy results we therefore move to a more comprehensive discussion of revenue productivity, starting with an examination of the link between the real exchange rate, its determinants, and revenue yields.

\section{Tax productivity and the real exchange rate}

Standard measures of revenue productivity express the tax flow in terms of GDP where, typically, both are measured in terms of current domestic currency. As a consequence there are two channels through which real exchange rate determinants (the 'fundamentals') may affect revenue. On the one hand, changes in the fundamentals directly alter the size and composition of the tax base. For example, balance of payments support may increase the total volume of imports and hence the level and composition of aggregate demand relative to GDP. The 
precise manner in which aggregate demand alters depends on consumer preferences and the structure of production. To the extent that the tax structure is not uniform across components of aggregate demand, this will alter the tax yield ceteris paribus. On the other hand, an increase in balance of payments support will alter the real exchange rate. This relative price effect has an impact on the revenue yield independent of the direct quantity effect as long as the relevant tax base has a composition (between tradable and non-tradable goods) different from that of GDP. For example, a real exchange rate depreciation will increase the domestic value of trade taxes relative to taxes levied on domestic production, when these taxes are levied ad valorem.

This presents an empirical problem when we seek to estimate revenue yields. In a fully reduced form, where we substitute the real exchange rate by its fundamentals, the coefficients on the fundamentals will reflect a composite of the direct and indirect (or relative price) effects. Hence in order to highlight both direct and indirect effects we estimate a "semi-reduced form" in which the real exchange and its determinants jointly enter the tax equations. In the following section we develop a simple model to illustrate this point. In doing so we distinguish three taxes, taxes on total GDP (our "income tax"), taxes on non-tradables (our "domestic indirect tax") and a tariff on imports (our "trade tax"). To simplify the analysis we assume that there are no domestic savings, investment or intermediate goods in the economy, and factors of production are fixed in supply and fully employed.

\subsection{The model}

We examine a small open economy facing world prices of $P_{X}$ and $P_{M}$ for its exports and imports, that produces and consumes a non-traded domestic good with price $P_{N}$. Exports are not consumed at home and there is no competing production of imports. However imports attract a tariff. Capital stocks are sector-specific while labour, denoted $L$, moves between sectors to equalize real consumption wages. Public expenditure is financed through the three (distortionary) taxes: $t$ on private sector production; $d$ on non-tradable production and consumption; and the tariff on imports, $\phi$. Relative prices are defined in terms of market rather than factor prices, hence the import real exchange rate is denoted

$$
Q=\frac{P_{N}}{P_{M}}=\frac{P_{N}}{P_{M}^{*}+\tau},
$$

where $\tau$ denotes the tariff and an increase in $Q$ denotes an appreciation. The export real exchange rate is $Q_{X}=P_{N} / P_{X}$ from which it follows

$$
\frac{Q}{Q_{X}}=\frac{P_{X}}{P_{M}}=\frac{P_{X}}{P_{M}^{*}+\tau}=T(1-\phi)
$$

where $T=P_{X} / P_{M}^{*}$ is the (exogenously determined) small country's terms of trade in international markets, and $\phi=\tau /\left(P_{M}^{*}+\tau\right)$ is the tariff expressed as a proportion of the tariff inclusive price.

Equilibrium holds when aggregate spending equals aggregate income at full employment and the trade balance is equal to the exogenous aid inflow (for simplicity we assume there are no private international capital movements or 
changes in reserves). Using revenue and expenditure functions (see Dixit and Norman, 1980), and denoting public and private expenditure functions and utility by lower- and upper-case letters respectively, we express this relationship as:

$$
e\left(P_{N}, P_{M}, u\right)+E\left(P_{N}, P_{M}, U\right)=R\left(P_{N}, P_{X} ; L\right)+P_{M} A .
$$

There is no government production in this economy: the government simply consumes the imported and non-tradable goods, although its preferences are not necessarily the same as those of the private sector. For convenience we normalize on the domestic price of imports $\left(P_{M}\right)$ and re-express (5) as

$$
e(Q, 1, u)+E(Q, 1, U)=R(Q, T(1-\phi) ; L)+A
$$

where $A$ is aid measured in units of imports, and $u$ and $U$ denote public and private sector utility. ${ }^{5}$ By the properties of the revenue and expenditure functions, letting subscripts denote partial derivatives with respect to the relevant arguments, we can express the supply and compensated demand functions for non-traded goods as $R_{Q}, e_{Q}$ and $E_{Q}$ respectively, leading to market-clearing condition in the non-traded goods market

$$
e_{Q}(Q, 1, u)+E_{Q}(Q, 1, U)=R_{Q}(Q, T(1-\phi) ; L),
$$

By Walras Law, (6) and (7) imply equilibrium in the tradable goods sector. GDP measured in imported goods is:

$$
R=Q R_{Q}+T(1-\phi) R_{T}
$$

where $R_{T}$ represents the supply of tradable goods. Public expenditure is financed through a tax on private sector income (excluding net aid inflows), the domestic sales tax and the tariff on imports. With no changes in foreign reserves and aid as the only capital inflow then the tax base for tariff revenue can be expressed in terms of the capacity to import (i.e. total exports plus aid valued at domestic import prices). Finally we allow for Tanzi effects so that the actual real revenue yield from each tax instrument is a (negative) function of the inflation rate, $\pi$. Tanzi effects are assumed to differ across the three taxes and are denoted $\alpha(\pi), \beta(\pi)$ and $\gamma(\pi)$ respectively for income taxes, indirect taxes, and trade taxes. These Tanzi effects represent the only price non-homogeneity in the model. Thus, with a balanced government budget, we define the revenue/expenditure of the public sector as

$$
\begin{aligned}
e(Q, 1, u)= & t(1-\alpha(\pi))\left(Q R_{Q}+T(1-\phi) R_{T}\right)+d(1-\beta(\pi)) Q R_{Q} \\
& +\phi(1-\gamma(\pi))\left(T(1-\phi) R_{T}+A\right)
\end{aligned}
$$

\subsubsection{Tax yields}

We can use this simple structure to express the three tax yields in terms of the (import) real exchange rate, the terms of trade, aid inflows and inflation.

\footnotetext{
${ }^{5}$ Note also that under this normalization we have $P_{M}^{*}+\tau=1$ and hence $\phi=\tau$.
} 
Defining the revenue yield for each tax as $Y_{i}$ for $i=t, d$, and $\phi$, we obtain:

$$
\begin{aligned}
Y_{t} & =\frac{t(1-\alpha(\pi))\left(Q R_{Q}+T(1-\phi) R_{T}\right)}{Q R_{Q}+T(1-\phi) R_{T}} \\
Y_{d} & =\frac{d(1-\beta(\pi)) Q R_{Q}}{Q R_{Q}+T(1-\phi) R_{T}} \\
Y_{\phi} & =\frac{\phi(1-\gamma(\pi))\left(T(1-\phi) R_{T}+A\right)}{Q R_{Q}+T(1-\phi) R_{T}} .
\end{aligned}
$$

Totally differentiating these revenue yields we get the following expressions for the evolution of the component tax yields, under the assumption that the tax rates are fixed at $t, d$ and $\phi .{ }^{6}$ For convenience we define the own- and cross-price elasticities of supply for tradables and non-tradables as:

$$
\sigma_{Q Q}=\frac{Q R_{Q Q}}{R_{Q}}, \quad \sigma_{T T}=\frac{T R_{T T}}{R_{T}}, \quad \sigma_{Q T}=\frac{T R_{Q T}}{R_{Q}} \quad \text { and } \quad \sigma_{T Q}=\frac{Q R_{T Q}}{R_{T}} .
$$

Denoting the non-tradable component of GDP by $n=Q R_{Q}$ and the tradable component as $s=(1-\phi) T R_{T}$, the total derivatives for each tax component are as follows:

$$
d Y_{t}=-t \alpha_{\pi} d \pi
$$

for income taxes,

$$
\begin{aligned}
d Y_{d}= & -d \beta_{\pi}\left(\frac{n}{n+s}\right) d \pi \\
& +d(1-\beta(\pi)) R_{Q}\left[1+\sigma_{Q Q}-\sigma_{T Q}\right]\left(\frac{s}{(n+s)^{2}}\right) d Q \\
& +d(1-\beta(\pi))(1-\phi) R_{T}\left[\sigma_{Q T}-\left(1+\sigma_{T T}\right)\right]\left(\frac{n}{(n+s)^{2}}\right) d T
\end{aligned}
$$

for indirect taxes, and

$$
\begin{aligned}
d Y_{\phi}= & -\phi \gamma_{\pi}\left(\frac{s+A}{n+s}\right) d \pi \\
& +\frac{\phi(1-\gamma(\pi)) R_{Q}\left[(1-\phi)(n-A) \sigma_{T Q}-(s+A)\left(1+\sigma_{Q Q}\right)\right]}{(n+s)^{2}} d Q \\
& +\frac{\phi(1-\gamma(\pi)) R_{T}\left[(1-\phi)(n-A)\left(1+\sigma_{T T}\right)-(s+A) \sigma_{Q T}\right]}{(n+s)^{2}} d T \\
& +\frac{\phi(1-\gamma(\pi))}{(n+s)} d A
\end{aligned}
$$

for tariffs. Although these expressions appear rather complicated it is possible to derive the following results under weak assumptions concerning the relative strength of own- and cross-price elasticities of supply.

\footnotetext{
${ }^{6}$ We do not examine the case where these rates are allowed to vary since in our empirical work we do not have data on explicit tax rates.
} 
Remark 1 [Inflation]. For $\alpha_{\pi}, \beta_{\pi}$, and $\gamma_{\pi}>0$ an increase in inflation reduces all tax yields.

Remark 2 [Real Exchange Rate]. (i) When the own-price elasticity of supply for non-tradables is sufficiently large relative to the cross-price elasticity, such that $\left(1+\sigma_{Q Q}\right)>\sigma_{T Q}$, an appreciation in the (import) real exchange rate, denoted by a rise in $Q$, increases the yield from domestic indirect taxes, and vice versa for a real exchange rate depreciation; (ii) when the own-price elasticity of supply is sufficiently large relative to cross-price effects, and the share of non-tradables in total GDP is not too large, such that $\left(1+\sigma_{Q Q}\right)>$ $\sigma_{T Q}(1-\phi)(n-A) /(s+A)$, an appreciation in the import real exchange rate decreases the yield from trade taxes, and vice versa for a real exchange rate depreciation; (iii) movements in the real exchange rate have no impact on the income tax yield.

Remark 3 [Terms of Trade]. (i) When the own-price elasticity of supply for tradables is sufficiently large relative to cross-price elasticity, such that $(1+$ $\left.\sigma_{T T}\right)>\sigma_{Q T}$, an improvement in the terms of trade, denoted by an increase in $T$, will reduce the yield from domestic indirect taxes and vice versa for a deterioration in the terms of trade; (ii) when the own-price elasticity of supply for tradables is sufficiently large relative to cross-price effects and the share of tradables in total GDP is not too large, such that $\left(1+\sigma_{T T}\right)>\sigma_{Q T}(s+A) /((1-$ $\phi)(n-A))$, an improvement in the terms of trade will improve the trade tax yield and vice versa for a deterioration in the terms of trade; (iii) movements in the terms of trade have no impact on the income tax yield.

Remark 4 [Aid]. An increase in the aid flow will have no impact on income taxes or domestic indirect tax yields but will lead to an increase in the trade tax yield.

These remarks highlight the anticipated differential responses of the components of total tax revenue to external and policy factors. It is clear that the net effect on total taxation will reflect the incidence of taxation and the composition of the tax base between the tradable and non-tradable components of domestic production and the level of aid.

\subsubsection{The real exchange rate}

So far we have taken the real exchange rate as parametric to the revenue equations. However it is useful to examine the properties of the real exchange rate itself. To do so we take the total differential of equations (6), (7) and (9) and solve for the three endogenous variables $d Q, d u$, and $d U$ in terms of the strictly exogenous variables (see Appendix for derivation). The solution for the real exchange rate is given by

$$
\begin{aligned}
d Q= & \left((1-\phi(1-\gamma(\pi))) D_{y}+\phi(1-\gamma(\pi)) d_{y}\right] \Phi d A \\
& +\left[D_{y}\left(\left(1-\tau_{2}\right)(1-\phi) R_{T}-\tau_{1} Q R_{T}-T(1-\phi) R_{T T}\right)\right. \\
& \left.+d_{y}\left(\tau_{2}(1-\phi) R_{T}+\tau_{1} Q R_{T}+T(1-\phi) R_{T T}\right)-(1-\phi) R_{T Q}\right] \Phi d T \\
& +\left[\left(t \alpha_{\pi}+d \beta_{\pi}\right) Q R_{Q}+\left(t \alpha_{\pi}+\phi \gamma_{\pi}\right) T(1-\phi) R_{T}+\phi \gamma_{\pi} A\right]\left(d_{y}-D_{y}\right) \Phi d \pi
\end{aligned}
$$


where $D_{y}=E_{Q U} / E_{U}$ and $d_{y}=e_{Q u} / e_{u}$ are the "Marshallian" income elasticities of demand for non-tradable goods by the private and public sector respectively, $\Phi=\left(R_{Q Q}-e_{Q Q}-E_{Q Q}\right)>0$ and $\tau_{1}$ and $\tau_{2}$ are the average tax rate on the tradable and non-tradable components of output, $t(1-\alpha(\pi))+d(1-\beta(\pi))$ and $t(1-\alpha(\pi))+\phi(1-\gamma(\pi))$ respectively. Although this is a cumbersome expression it is easy to see that if public and private demand functions for non-tradables exhibit the same income elasticity so that $D_{y}=d_{y}$ we get the following expression:

$$
d Q=D_{y} \Phi d A+\Phi(1-\phi)\left[D_{y} R_{T}-R_{T Q}\right] d T
$$

This expression summarises the following key results. First, we get the standard result that an increase in aid unambiguously appreciates the import real exchange rate (assuming that non-tradable goods are normal goods). Second, the effect of an improvement in the terms of trade depends on the whether the income or substitution effect dominates. If the income effect dominates then $D_{y} R_{T}>R_{Q T}$ so that the second term is positive, indicating a real exchange rate appreciation. The third result is that under the restriction that $D_{y}=d_{y}$ changes in the rate of inflation have no impact on the real exchange rate. In this model there is long-run price homogeneity so that inflation represents a pure transfer from the public to the private sector through the operation of the Tanzi effect. With equal income elasticities of demand in both sectors the real exchange rate consequences of the transfer are neutralized. Clearly if the assumption $D_{y}=d_{y}$ is relaxed the model admits a role for inflation.

Equations (11) to (15) provide a summary of a "semi-reduced form" specification for the tax yields and the real exchange rate which we now proceed to estimate.

\section{The empirical model}

We estimate empirical counterparts to $(11,12$, and 13) within a dynamic panel data structure of the form:

$$
\left(\frac{t}{y}\right)_{j i t}=\alpha_{j}+\beta_{j}\left(\frac{t}{y}\right)_{j i t-1}+\gamma_{j} \mathbf{X}_{i t}^{\prime}+u_{i t} .
$$

Our sample consists of annual observations over the period 1980-1996 for a panel of 22 countries. A number of points need to be made about the model. First, it is estimated for four tax shares $\left(\frac{t}{y}\right)_{j}$ where $j$ denotes income taxes, ytax_y, domestic indirect taxes, itax_y consisting of domestic sales taxes and excise duties, taxes on international trade, $\operatorname{ttax}_{-} y$, and the aggregate, total tax revenue, txrev_y. The split between itax_y and ttax_y attempts to mirror the theoretical distinction between taxes on non-tradables and tradables. The distinction is not well maintained in practice: in many regimes domestic taxes are levied on traded goods on top of the explicit trade duties. In the limit, if all domestic indirect taxation was of this form, we would expect the revenue functions for these two components of the tax share to behave in a similar fashion. By contrast, the 
greater the share of 'pure' non-tradables in the tax base, the more the behaviour of the two components will differ.

Second, the vector $\mathbf{X}_{i t}^{\prime}$ of explanatory variables includes the factors discussed in the model above; the (import) real exchange rate, aid, the terms of trade, inflation and the openness of the economy to trade). In addition, and drawing on other literature in this area, the vector also includes variables to control for the level of real income and the composition of production and output (see Leuthold, 1996).

Third, in contrast to the theoretical model, which derives the consequences of movements in the equilibrium real exchange rate, we examine whether there is a differential effect between equilibrium and disequilibrium movements in the real exchange rate.

Finally, since revenue shares tend to be strongly persistent over time, (16) is estimated as a first order dynamic panel data model. To control for the so-called "Nickell bias" arising from the lagged dependent variable and to control for the possible endogeneity of aid, the real exchange rate and per capita income we use a GMM estimator (see Arellano and Bond, 1998). Heteroscedastic robust standard errors are computed using White's sandwich-estimator. However, this model, and also the real exchange rate equation reported below, is from the class of potentially heterogenous dynamic panel models hence the estimates of the coefficient vector $\theta_{j}=\left\{\alpha_{j}, \beta_{j}, \gamma_{j}\right\}$ are vulnerable to the aggregation biases discussed by Pesaran and Smith $(1995)^{7}$. Given the relatively short time dimension of the panel the Pesaran and Smith recommendation that the individual micro-relations should be estimated separately and the averages of the estimated micro-parameters calculated explicitly is not feasible in this instance. However, given the specification of our model which uses interactive group and time dummy variables to specifically allow for parameter heterogeneity across the two exchange rate regimes and time (if not across individual cross-section units) the extent of this potential bias is likely to be reduced.

Initially we estimate a version of the model which imposes pooling restrictions across both country groups and over time, while allowing for countryspecific fixed effects. Subsequently we re-estimate the model by allowing the group- and time-pooling restrictions to be relaxed along two axes. The first is between CFA and non-CFA countries and the second between the early part of the sample and the latter part. We handle this by including interactive group and time dummy variables for the key determinants. First, however, we estimate the equilibrium and disequilibrium components of the real exchange rate.

\subsection{Real exchange rate decomposition}

The tax equations discussed above are based on equilibrium movements in the real exchange rate. However it is widely accepted that across all countries in the sample there have been periods of substantial real exchange rate misalignment and it is possible that equilibrium and disequilibrium movements in the real exchange rate have different consequences for revenue productivity. In order to investigate this possibility we estimate a model for the long-run real exchange

\footnotetext{
${ }^{7}$ Pesaran and Smith note that if there is cross-section heterogeneity in the true coefficient vector and if the regressors are serially correlated, coefficient estimates derived from a pooled model will be biased and inconsistent and typically cannot be addressed by standard IV methods.
} 
rate and use this to decompose changes in the actual real exchange rate into 'equilibrium' and 'disequilibrium' components. Given the limitations imposed by the size of our data panel we do not estimate the model country-by-country but instead we exploit the panel to define a region-wide "common" model for the real exchange rate and use this as the basis for estimation of the equilibrium and disequilibrium components for each country. The estimating equation is based on equation (14) above and is estimated on the pooled sample (allowing for country-specific fixed effects). In addition to the aid and terms of trade effects we also include as regressors real per capita income (lypc), a measure of openness to trade and the level of recurrent government consumption (lgy). In addition, we distinguish between the components of the net resource transfer by including (the log of) the resource flow on aid (denoted lga) and (the log of) interest costs ( $\operatorname{lin})$ separately. The first column of Table 4 reports the model estimated using a fixed effects estimator while the second re-estimates the model by disaggregating the terms of trade. In the third column we use an instrumental variable estimator to control for the potential endogeneity of the measure of openness and net disbursements on aid, where the 'beta coefficients' from column two provide an indication of the relative importance of each of the regressors. ${ }^{8}$

$$
\text { *** Table } 4 \text { here } * * *
$$

Although the model is estimated across countries rather than simply over time it is relatively data coherent and the results conform to the results found in the time-series literature (see for example Elbadawi, 1994, Elbadawi and Soto, 1997 and Baffes et al 1999). The model explains a relatively high proportion of the cross-country variation in the real exchange rate and, moreover, controlling for country-specific effects, the data comfortably accept the restriction that the slope coefficients are constant across the two nominal exchange rate regimes. Hence we conclude that our model provides a valid statistical basis for decomposing the real exchange rate. Turning first to an interpretation of the common model we note that, other things equal, the higher the interest burden and the higher the cost of imports, the more depreciated the real exchange rate. Similarly the results on the openness measure supports the notion that trade-liberalizing reforms depreciate the real exchange rate. Offsetting these factors income effects from higher per capita GDP, higher export prices and net aid inflows generate the conventional tendency towards a real exchange rate appreciation.

Comparing columns 1 and 2 we note that the real exchange response to export and import price movements is asymmetric: the net terms of trade effect is dominated by movements in export prices. This is consistent with the empirical literature estimating real exchange rates for small open economies which tends to find strong income (and comparatively weak substitution) effects associated with export price movements, especially when the export sector is commodity based. In our sample, the asymmetry is quite pronounced with import prices having on average no significant impact on the real exchange rate implying that

${ }^{8}$ The beta coefficient for regressor $j$ is defined as

$$
\text { beta } a_{j}=\frac{\beta_{j} \sigma_{x j}}{\sigma_{y}}
$$


on average the income and substitution effects from changes in the world price of imports are more equally balanced. Somewhat surprisingly in the light of existing literature, it would appear that the relationship between government expenditure and the real exchange rate cannot be established with precision. Finally, the evidence on the disaggregated components of the net aid flow suggests that the real exchange rate responds to a greater degree to increased interest costs than to net aid flows. Again this result is consistent with theory: higher interest costs lead unambiguously to a depreciation of the real exchange rate while net aid inflows consist in part of demand side effects (strengthening a tendency towards appreciation) but also support the expansion of aggregate supply which may be expected to have an offsetting effect on the real exchange rate, especially if aid relaxes production or other bottlenecks. ${ }^{9}$

Given the economic and statistical coherence of the real exchange rate model we proceed to use it to define the "long run" or equilibrium real exchange rate for each country so that deviations from this equilibrium represent the relative over- or under-valuation of each country's real exchange rate. In the absence of a full-blown cointegration analysis we define the equilibrium by fitting the final model in Table 4 to long-run values of the country-specific explanatory variables which are computed using the Hodrick-Prescott filter ${ }^{10}$ and use this measure to decompose the actual real exchange rate for each country into a measure of the equilibrium real exchange rate and the misalignment of the actual real exchange rate from this equilibrium. The equilibrium real exchange rate is denoted lerer while the measure of misalignment is denoted mis. Both are reported in Table 2. By convention a depreciation in the equilibrium real exchange rate is represented by an increase in lerer. For the misalignment measure, a negative (positive) value of mis corresponds to an overvaluation (undervaluation) of the real exchange rate relative to its estimated equilibrium. Thus an increase in the variable indicates a move from relative over- to under-valuation. Both regions experienced a steady depreciation in the equilibrium real exchange rate but while the non-CFA countries eliminated their initially very large misalignment during the late 1980s, the actual real exchange rate in the CFA zone remained, by our measure, substantially overvalued throughout the period until the devaluation in January 1994. Only then was the progressive overvaluation eliminated.

\subsection{Revenue equations}

We are now ready to examine the revenue equations. Table 5 reports the preliminary results of estimating equation (16) for the three components plus the aggregate total tax revenue measure under the assumption that revenue be-

\footnotetext{
${ }^{9}$ Although not reported here it is possible to show that the balance between these demand and supply effects shifts over time.

${ }^{10}$ The Hodrick Prescott filter applied to any series $y_{t}$ defines a "smoothed" series by minimizing

$$
\sum_{t=1}^{T}\left(y_{t}-s_{t}\right)^{2}+\lambda \sum_{t=2}^{T-1}\left(\Delta s_{t+1}-\Delta s_{t}\right)^{2} .
$$

with respect to $s_{t}$. In other words the filter minimizes the variance of $y_{t}$ around $s_{t}$ subject to a penalty (determined by the parameter $\lambda$ ) that constrains the second difference of $s_{t}$. As $\lambda \rightarrow \infty$ the smoothed series $s_{t}$ tends to a linear trend while as $\lambda \rightarrow 0$ the filter tends to $y_{t}$. We set the smoothing parameter to 100 which is generally agreed to be valid for annual data.
} 
haviour can be pooled across the exchange rate regimes (although we allow for country-specific effects). These pooled results, which correspond to those estimated by Ghura (1998), establish a benchmark against which we can examine the consequences of relaxing the assumption of common group effects. A number of regularities emerge from the pooled model. For income taxes, domestic indirect taxes and total tax revenue the long income elasticity of tax revenue (i.e. the buoyancy of the tax system) is marginally greater than unity (although only significant for income taxes), while for trade taxes the elasticity is slightly less than unity. ${ }^{11}$ The agriculture share in total production has a positive (and marginally significant) impact on trade taxes but a negative and significant impact on income tax yields while the industrial share has a positive effect on yields - although this is only significant in aggregate. Government expenditure has a positive effect on indirect and trade taxes, but no marked effect on income taxes, while openness raises trade taxes and lowers indirect taxes.

$$
\text { *** Table } 5 \text { here } * * *
$$

Inflation effects are uniformly negative and relatively significant across all tax yields although the effect is relatively weak (the long-run point elasticity is in the region of 0.04 for each component suggesting that a $100 \%$ increase in the inflation rate (doubling the average inflation rate from $20 \%$ to $40 \%$ per annum) would decrease the revenue yield by around 4 percent (of the yield, not percentage points). Terms of trade effects have a stronger and more significant impact on trade taxes (and total taxes) than on indirect and income taxes although the consequences of a change in the terms of trade are not symmetrical between falling import prices and rising export prices. Rising export prices improve (albeit with only a weak significance) the income- and trade-tax yields while rising import prices (the case effectively analyzed in the model presented above) have uniformly negative effects on revenue yields, and in this case the effect is significant for trade- and total taxes. This is consistent with the theoretical model (rising import prices imply a worsening of the terms of trade).

Finally, we turn to the real exchange rate. Since we are already controlling for the real exchange rate fundamentals, the coefficients on the real exchange rate terms represent only the indirect or relative price effect of the real exchange rate on revenue. Recall that an increase in the real exchange rate indicates an equilibrium depreciation of the real exchange rate whilst an increase in the misalignment measure similarly measures the elimination of overvaluation (or accentuation of an undervaluation). Hence, in a casual sense, the signs of these two variables move together. More surprising is that contrary to the theoretical model presented in Section 3 a depreciation in the real exchange rate improves indirect tax yields and worsens the trade tax yield. Moreover this effect is the same (at least in terms of direction) whether we consider equilibrium or disequilibrium measures of the real exchange rate. One possible explanation for this peculiar result is that it reflects an inappropriate aggregation, either across groups or over time. Our next step is to investigate this possibility, where we use the pooling results to provide a guide to re-specification.

\footnotetext{
${ }^{11}$ The buoyancy can be defines as $\left(1+\beta^{*}\right)$ where $\beta^{*}$ denotes the long-run coefficient on lypc. At average values of the tax ratios, this translates into a (long-run) partial income elasticity of the tax share of approximately 0.6 for income taxes, 0.67 for indirect taxes and 0.13 for total tax revenue. For trade taxes, the sign is reversed: higher real incomes are associated with a reduced trade tax yield ceteris paribus.
} 


\subsubsection{Pooling restrictions}

The question we pose is whether the slope coefficients, the vector $\gamma$ in equation (16), are constant over time and between groups. We cannot estimate a wholly time-varying coefficients model and therefore we seek a feasible basis for disaggregation. The cross-section disaggregation between CFA and non-CFA countries is self-evident. Less clear is how we should examine stability over time. A natural cleavage to examine is around the middle of the sample (i.e. the late 1980s) which coincides with substantial adjustment efforts, especially by non-CFA countries. However we may also wish to know whether the CFA devaluation represented a significant break-point. To refine our specification, we employ standard break-point Chow tests using the models estimated in Table 5 in which we allow for a single break to occur in the non-CFA sample in the window 1986-1992. We follow the same strategy for the CFA countries but in order to examine whether there is evidence of a break prior to the devaluation we restrict the sample to 1980-1993 inclusive and the break window to 19861991. We then also allow for a possible break in 1994 arising from the CFA devaluation. The break point tests, which in this instance are tests of the null that the conditional variance of the model is constant across the break-point, suggest that there is significant non-constancy over time (across the two country groupings) indicating that the 'most likely' break points are after 1989 for the non-CFA countries and after 1987 for the CFA countries. ${ }^{12}$ This suggests the following potential five-way disaggregation:

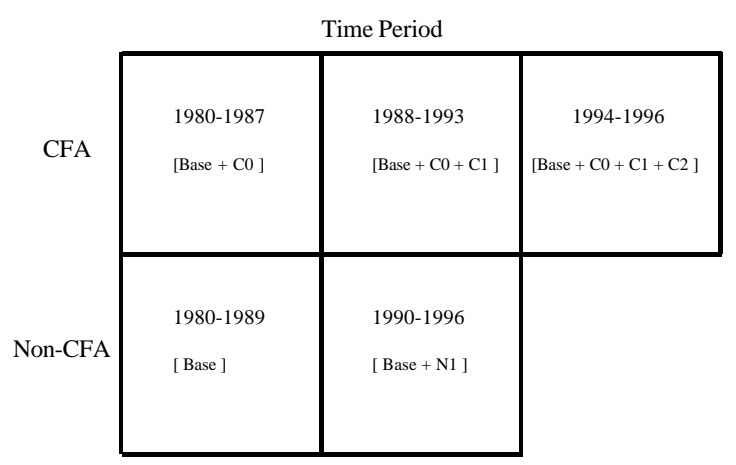

This disaggregation is used to define time- and group dummy variables corresponding to each cell of the matrix which we interact with the vector of regressors $\mathbf{X}$. The baseline is represented by the non-CFA countries for the period 1980-89 and we define dummy variables for non-CFA countries during the period 1990-96 and the CFA countries over the three time periods. Denoting these as $N 1, C 0$, $C 1$, and $C 2$,the net impact for each time and country group is given in the figure above. This categorization necessarily increases the dimensionality of the empirical model very significantly with the attendant costs in terms of the efficiency of the estimators. However, as anticipated from Table 5 it is possible to restrict a large number of the interactive dummy variables to zero (i.e. we can accept sub-pooling restrictions). In particular, we find that it is possible to define a model that spans the CFA franc devaluation of January 1994 without significant

\footnotetext{
${ }^{12}$ Details of the break-point tests are available on request from the corresponding author.
} 
loss of information. In other words, controlling for the determinants of revenue productivity (the values of which may have changed due to the devaluation) and allowing for the other disaggregations, the data support a constant parameter model for the CFA countries across the period from 1988 to 1996. To some extent this result is not surprising: given the relatively short post-devaluation period we cannot expect to estimate with precision the values of the interactive terms over this sub-sample. Even so, the point-estimates themselves were also economically small which leads to our first main conclusion namely that there are no statistical grounds for suggesting that the fundamental determinants of revenue productivity changed substantially as a result of the CFA devaluation, at least in the short run.

Exploiting this fact, we impose the restriction that the "late" period for the CFA countries can be defined to run from 1988-96 and re-estimate the model over four instead of five sub-categories. Table 6 reports the final results of an extensive general-to-specific reduction in which valid pooling restrictions are imposed. Nonetheless Table 6 contains a huge number of results. To make sense of these we start by discussing them on a tax-share by tax-share basis, but in the final section we pull the results together by relating back to the key stylized facts discussed in the introduction. By the nature of the chosen semi-log specification, where the dependent variable is the tax share, the size of the marginal effects is difficult to interpret, and therefore Table 7 expresses the results in terms of "long-run" elasticities evaluated at the mean value of the variables for each group and time period. ${ }^{13}$

$$
\text { *** Tables } 6 \text { and } 7 \text { here } \text { h** }^{*}
$$

\subsubsection{Statistical features of the results}

The equations in Table 6 fit the data substantially better than the raw buoyancy results in Table 3 and the pooled revenue equations in Table 5. The models, estimated by GMM, explain 40 and 60 percent of the variation of tax shares across the sample after conditioning on country-specific unobservable effects, which are strongly significant across all revenue shares. As we noted, these fixed effects reflect the unobservable time-invariant determinants of the revenue yield including the stance of the tax structure. Figure 3, which plots the values of the country-specific fixed effects (ordered alphabetically within the two exchange rate regimes starting with the CFA countries) highlights an important feature of the data. Given that the slope coefficients differ between the groups so that the regression lines are not parallel in the relevant dimensions, the observed differences in the country specific intercepts between the CFA and non-CFA groups (such as observed for indirect and trade taxes) cannot be extrapolated to any value of the vector of explanatory variables. For instance, we cannot use this information to claim that, at the mean of the vector of the independent variables, indirect taxes will be higher and trade taxes lower in the CFA compared to the non-CFA (which we could infer if the slope coefficients were identical). However, the Figure does provide evidence to strongly suggest that for total taxes, indirect

\footnotetext{
${ }^{13}$ Values for the partial elasticities in Table 7 will therefore differ either because the semielasticities are different (as indicated in Table 6) or because of the difference in the sub-sample values at which the elasticities are evaluated.
} 
and trade taxes the amount of within group variation is very low relative to the between group variation. ${ }^{14}$

Figure 3.
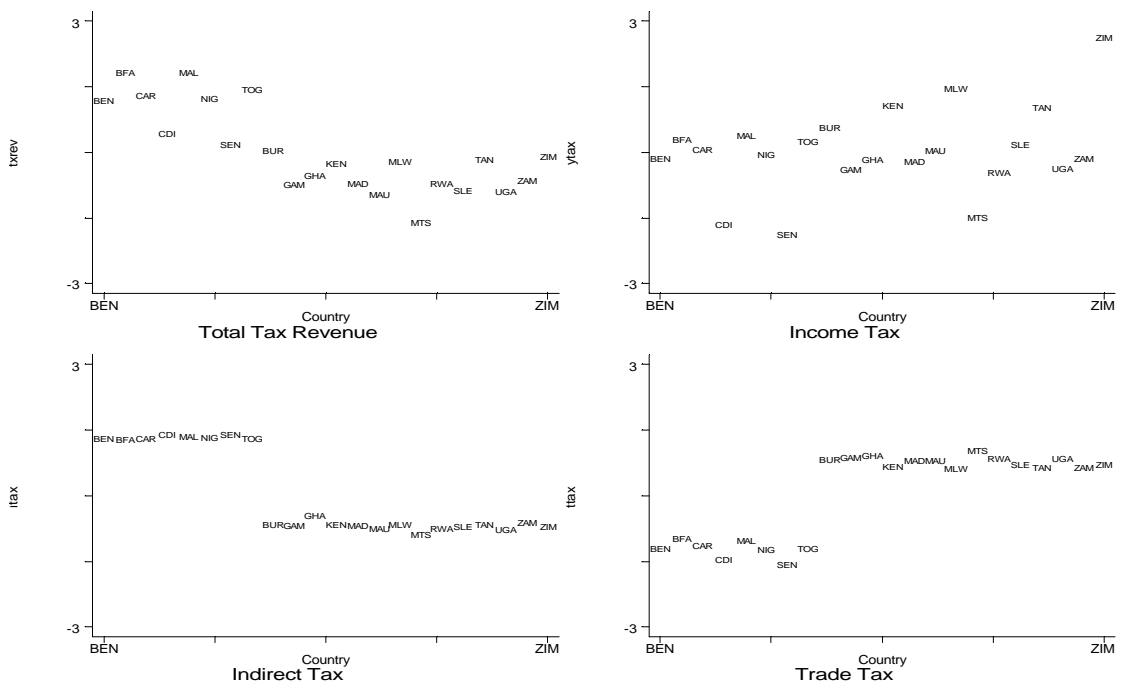

Standardized Country Specific Effects

Although the fixed effects provide insight into the poolability within the two country groupings they cannot provide evidence on the evolution over time of the tax regime, although we do know that there has been a series of trade liberalizations in both groups of countries. Given that we are modelling the gross tax yield, trade reforms will necessarily induce an omitted variable bias in the coefficients on variables correlated with trade liberalization, particularly net aid flows and the openness of the economy. To the extent that tax rates have been on the 'good' side of the tax Laffer curve so that trade liberalization would be expected to lower the average tax yield, the coefficient on variables positively correlated with trade liberalization will therefore be biased downwards.

Given that the impulse for tax reform was relatively common across the continent as a whole, we can argue that the implied time-dummy variables actually control for the evolution of the tax regime (and hence mitigate the omitted variable bias problem). F tests against the null that the time dummy variables are jointly insignificant are reported in Table 6 and indicate that there is little evidence that time dummies for income or indirect taxes are significant. For trade taxes, we reject the null. As Figure 4 shows there is evidence of a steady decline over time in the trade-tax yield particularly from the late 1980s onwards. It is reasonable to suggest, therefore, that the time-dummies for the trade-tax equation control, at least in part, for the unobservable effects of trade reforms.

\footnotetext{
${ }^{14}$ This is borne out by standard tests of differences in the mean. The t-statistics against the null of no between groups difference are -1.44 for income taxes, 71.01 for indirect taxes, -25.43 for trade taxes and 7.31 for total taxes.
} 
Figure 4.

Revenue Equations Time Dummy Variables (as percent of GDP)

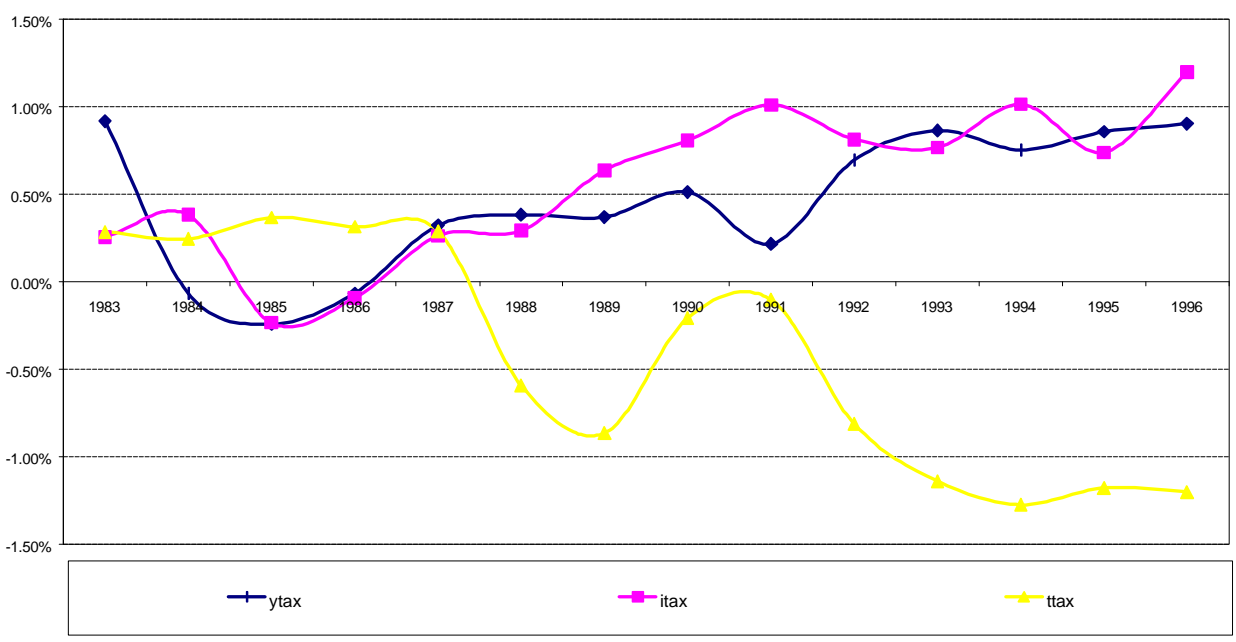

Finally the Sargan tests suggest that we have a valid set of instruments for the endogenous variables (the lagged dependent variable, net aid flows and openness) and that the model is free from significant error auto-correlation, suggesting that the GMM estimators are consistent and asymptotically efficient (although given the short time-dimension of the sample these tests are likely to have relatively low power).

\subsubsection{Revenue shares}

Total tax share We start our discussion of the final results by focussing on the structural determinants of total tax revenue (income and the structure of production) before turning to the role of the real exchange rate and its determinants. Given the semi-log functional form of the revenue equations it is convenient to express the income elasticity of revenue in terms of a (partial) buoyancy measure with respect to per capita real income. ${ }^{15}$ Buoyancy in both country groups is significantly in excess of unity although for the non-CFA countries there is evidence of a slight decline over time. Given this, however, the composition of production matters: total tax productivity is decreasing in the agricultural share over time and increasing in the industry share, although the former effect is generally stronger than the latter. The results on the openness of the economy are interesting: the trade share in total output has a strongly positive (but weakening over time) effect in the CFA countries but is not significant in determining total tax revenue in the non-CFA countries. As we shall see below, this appears to reflect features of the aggregation.

${ }^{15}$ The buoyancy measure is defined as

$$
b_{y}=\frac{\partial t}{\partial y} \cdot \frac{y}{t}=(1+\hat{\beta}) .
$$


Turning to the factors more central to this paper, we note the following. First, the effect of inflation is significant across all countries and over time. The semi-elasticity of inflation is constant across countries (Table 6) implying that in all countries a unit increase in the inflation rate has the same effect on the tax yield. However, given that the level of inflation varies substantially across countries and over time, this common semi-elasticity translates into variation in the full inflation elasticity ranging from -0.05 in the non-CFA countries to -0.01 in the CFA zone. These magnitudes are relatively low: for the non-CFA countries a doubling of the inflation rate from its mean value of $25 \%$ would reduces the total tax yield by around four percent of its mean yield or 0.6 percentages points of GDP.

The effect of the terms of trade is also broadly comparable across the country groups although the size of the effect is more pronounced in the CFA countries. Consider first the non-CFA countries. During the 1980s there appeared to be no systematic response of total revenue to movements in the terms of trade in the non-CFA countries. This changes, however, as we move into the later period. Here a $10 \%$ improvement in the terms of trade in both regions (for example through an equi-proportionate increase in the export price index and a fall in the import price index) would generate an improvement in the tax share of around $6 \%$ (of its mean value). For the CFA countries the effect is more stable throughout the whole sample although there is a small increase in the elasticity (from around 0.6 in the early 1980s to around 0.8 in the late 1980s and 1990s). That these effects appear significant only in the latter part of the period may reflect the sharp move away from quantitative restrictions on international trade which dominated many trade regimes in the early 1980s. These effects are not, however, symmetric nor are they consistent over time. For the non-CFA countries (and the CFA prior to 1988) higher export prices are associated with higher overall tax and rising import prices with lower revenue, but the latter effect is marginally stronger. This asymmetry reflects both the differential taxation of exports and imports but also the differential taxation of imports and domestic production in the presence of substitution in consumption between imports and domestic goods. If domestic production is taxed at a lower rate on average than imports then substitution away from imports will reduce total revenue. For the CFA countries post-1988, the response to movements in export prices is greatly increased while a rise in import prices actually appears to increase revenue. The peculiarity of these results will be explored in more detail below when we examine the disaggregated tax shares.

The role of government consumption expenditure also differs significantly between country groups. During the 1980s government expenditure in the nonCFA countries has a positive effect on the tax yield (with a marginal elasticity of 0.3) but by the 1990s this effect had declined to less than 0.07. By contrast higher government expenditure has been negatively associated with total tax revenue in the CFA zone. As the disaggregation by tax components suggests, most of the explanation for this differing behaviour lies in the behaviour of indirect taxes. By contrast with non-CFA countries where both indirect and trade tax revenue is increasing in the level of government expenditure, indirect tax revenue is reducing in the level of government expenditure, ceteris paribus, suggesting that in the CFA zone government expenditure is disproportionately exempt from indirect taxes.

Although net aid inflows had no significant effect on total tax revenue in the 
CFA countries or, indeed, in non-CFA countries in the 1980s, there is evidence of a small positive effect for the latter group in the 1990s. Recall that since we are controlling for the relative price effect of the real exchange rate and the trade share in GDP in this equation, the coefficient on net aid measures only the direct resource-transfer effect of the aid flow.

Finally we consider the role of the real exchange rate. Here the effects are particularly interesting - even though they may be slightly counterintuitive. A depreciation in the equilibrium real exchange rate has a positive (and increasing) effect on total tax revenue in the non-CFA countries. In other words, the relative price effect from the average equilibrium depreciation in the real exchange rate had a powerful positive impact on revenue. Contrast this trajectory with the CFA zone. Real exchange rate depreciations in these countries tends to worsen total tax revenue, while removal of real exchange rate disequilibrium also reduces the tax yield (for reasons noted below). This is a dramatic difference, but one which would appear to be explicable only when we examine the behaviour of the components of total taxation.

Disaggregated tax shares To fully understand the differential revenue performance between the two regions, it is useful to examine the components of total tax in more detail: these can be examined from columns 2 to 4 of Table 7. The first important conclusion is that very little of the overall difference in the revenue functions can be explained by differences in the income tax equations. Hence the structural effects (the income elasticity and the structure of production), are relatively similar and consistent across time and country groups although they appear to be somewhat more important for the CFA zone. The level of government expenditure is not a significant determinant nor, as suggested by the theoretical model above, does aid have a significant impact on the income tax yield. However for all countries the inflation effect is negative and significant. Neither terms of trade effects nor movements in the equilibrium real exchange rate affect income tax yields in the non-CFA countries (again as the theoretical model would suggest). For the CFA countries, not only do movements in the terms of trade appear to be significant, but the real exchange effect is strongly positive in the $1980-87$ period although it weakens substantially in the later period. Given that over the early period the real exchange rate was appreciating (a reduction in the value of lerer) this implies a reduction in the tax yield ceteris paribus. The semi-elasticity of the misalignment measure is also constant across all countries, although since the average misalignment is falling in the non-CFA countries over time and rising in the CFA (at least up to 1994) the misalignment effect is somewhat larger in the latter group. Recalling that an increase in the variable mis represents a movement from being more to less overvalued, this suggests that a movement towards equilibrium hurts income tax revenue.

Having said this, we really only begin to get a clear picture of how the two zones differ when we look at the results for indirect taxes and for taxes on trade. The first interesting point is that for indirect taxes, with the exception of the real exchange rate effects on trade taxes, the CFA models exhibit constant parameters over time (we can restrict all the interaction terms for the late CFA period to zero). Differences in the point elasticities therefore reflect changing values of the dependent and independent variables only. 
The second important feature of these results is the way in which factors leading to improvements in revenue performance in non-CFA countries are not reflected in the CFA country groups. This is seen most clearly through the effect of the real exchange rate on trade tax yields. As suggested in the theoretical model, a depreciation in the real exchange rate will lead to an increase in the trade tax yield for sufficiently large elasticities of supply for non-tradables. The results suggest that over time the trade tax revenue yield in the non-CFA zone has become significantly more responsive to movements in the (equilibrium) real exchange but this has not been the case for CFA countries. This increased flexibility works both ways: while non-CFA countries enjoy relative revenue gains in the presence of a depreciation in the real exchange rate their trade tax revenue will fall faster than in the CFA countries as the real exchange rate appreciates.

The third feature of the results is the distinctly different response of domestic indirect taxes to equilibrium and disequilibrium movements in the real exchange rate between the two groups of countries. Real exchange rate depreciations (both equilibrium and misalignment) tend to increase the indirect tax yield for the non-CFA countries but to decrease the tax yield for CFA countries, suggesting that in the CFA the tax base is dominated by non-tradables relative to that in the non-CFA countries. In a system where non-tradables constitute a large proportion of the tax base, and especially in the peculiar institutional setting of the CFA zone where neither expenditure switching nor expenditure reduction is required to sustain external balance, the revenue system will exhibit high buoyancy when the real exchange rate appreciates (and over appreciates). However when expenditure reduction is accompanied by a devaluation of the real exchange rate the revenue yield will collapse sharply. This stands in contrast to a system where tradable goods dominate the tax base and where the effects of expenditure switching and expenditure reduction offset each other.

The disaggregation also provides some insight into the evidence from the total tax yield results that indicated poorly defined effects of net aid flows. Controlling for the relative price effects, it would appear that net aid inflows have no impact on trade tax yields but they do have an effect on indirect taxes. In the early part of the sample there was a clear tendency for indirect tax revenue to decline in the presence of increased net aid flows. This tendency has continued for the CFA countries (and indeed has strengthened slightly) but has been reversed in the non-CFA countries so that post 1989 we observe a small overall positive aid elasticity. Two factors are likely to be important. On the one hand, the 1980s saw a switch away from aid as project support (in which case aid-financed imports were frequently tax and duty free) towards programme aid in which aid flows financed private sector imports that were not tax and duty free. Supporting this switch was a general move to close tax and duty exemption loopholes on aid projects in general.

Perhaps the most confusing results to interpret concern the terms of trade. We noted above that the total tax yield is positively related to the terms of trade. The results for the non-CFA countries are consistent with this outcome and reflect the predictions of the theoretical model: an increase in the terms of trade improves the trade tax yield,deteriorates the indirect tax yield, and has no measurable impact on the income tax yield. When we consider the separate effects of movements in export and import prices, the picture becomes less clear. For trade taxes the results suggest that rising export prices improve trade tax 
revenue while the world price elasticity of substitution in consumption of imports is sufficiently strong to lower trade tax revenue. Turning to indirect taxes we note that rising import prices raise indirect taxes which is consistent with the strong price elasticity of substitution in consumption away from imports. At least initially, however, rising export prices reduce indirect tax revenue.

For the CFA countries the results are less clear. For both trade taxes and indirect taxes the net terms of trade effect is negative. This raises at least two puzzles. The first is that according to the theoretical model we would not expect to see the same response of indirect and trade taxes to a terms of trade change, and the second is simply that the sign of the terms of trade effect suggests that the sharp decline in the terms of trade that occurred during the period should have benefitted rather than harmed the CFA countries. One reason why this may not have been the case is suggested by the two components of the terms of trade. We noted above that for the non-CFA countries rising import prices worsen trade tax revenue through a strong price elasticity of substitution in consumption from tradables to non-tradables. For the CFA countries, however, it would appear that this substitution effect is weak (possibly reflecting the high level of integration with the French economy) so that rising world prices raise trade tax revenue, with the corollary that the tax spillover to indirect taxes will be correspondingly weaker. Reinforcing this effect, however, it appears that rising export prices reduce both trade and indirect tax yields, weakly in the case of trade taxes but quite strongly in the case of indirect taxes. It is this latter effect which dominates the overall terms of trade effect on indirect taxes. There are a number of mechanism through which rising (falling) export prices may lead to falling (rising) trade and indirect tax revenue (controlling for the revaluation effects of movements in the real exchange rate), including the structure of export taxation and the input intensity of production in export and non-export sectors. Unfortunately the lack of data on either limits our ability to unpick this particular result.

\section{$5 \quad$ Summary and conclusions}

The results presented in Tables 6 and 7 are comprehensive but somewhat overwhelming. To provide a more coherent summary of the results we return to Figure 1 and pose the following question: how much of the difference in the tax yield can be attributed to "external factors" and how much to the response of the CFA countries to the changing external environment. We tackle this issue by constructing three simple counterfactual scenarios which allow us to decompose the gap between the average revenue yields in the two country groups. The three counterfactuals are illustrated in Figure 5. Using the subscripts $C$ and $N$ to denote CFA and non-CFA countries the (implied) models of the tax yield in CFA and non-CFA countries can be written as

$$
\hat{y}_{C}=\hat{\beta}_{C} X_{C} \quad \text { and } \quad \hat{y}_{N}=\hat{\beta}_{N} X_{N}
$$

respectively. The first counterfactual asks how the average outcomes in the CFA countries would have differed had these countries been confronted with the environment prevailing in non-CFA countries. Counterfactual 1 is thus defined 


$$
\hat{y}_{C}^{C F 1}=\hat{\beta}_{C} X_{N}
$$

and partitions the tax gap $\left(\hat{y}_{N}-\hat{y}_{C}\right)$ into two components. The first is the area below the counterfactual line, equal to $\hat{\beta}_{C}\left(X_{N}-X_{C}\right)$, which provides a measure of the amount of the revenue gap explained by differences in the environment, broadly defined to encompass all the explanatory variables defined by the vector $\mathbf{X}$ in (16). The area above the line, equal to $\left(\hat{\beta}_{N}-\hat{\beta}_{C}\right) X_{N}$, measures, in some crude sense, differences in policy responses to the same environment. Through this partition, it would appear that by the mid-1990s approximately half the revenue gap could be explained by difference is the "environment", and half as a result of "behavioural" responses to these differences in the environment.

Counterfactual 1 implicitly assumes that all the elements of the vector $\mathbf{X}$ are exogenous to the policy process. Certainly the vector contains structural characteristics, such as the composition of production, the terms of trade, the level of per capita income and the equilibrium real exchange rate which are independent of the conduct of macroeconomic policy, at least in the shortrun. However $\mathbf{X}$ also contains factors more closely under the control of the authorities including the rate of inflation and the degree of misalignment of the real exchange rate. In Counterfactual 2 we therefore isolate the contribution of the difference in the environment made by these so-called "policy factors" from the structural factors. We define the counterfactual as

$$
\hat{y}_{C}^{C F 2}=\hat{\beta}_{C} X_{C}+\hat{\beta}_{C P}\left(X_{N P}-X_{C P}\right)
$$

where the subscript $P$ denotes the policy components of $\mathbf{X}$. Counterfactual 2 thus measures the contribution of the policy stance to total tax revenue performance. Roughly speaking, when the CF2 lies below the actual trajectory of CFA tax revenue the actual policy stance of the CFA countries worked in their own favour, and vice versa when CF2 lies above actual revenue. Thus in the early 1980s the lower inflation and lower real exchange rate misalignment in the CFA zone implied total revenue was higher (to the tune of $0.75 \%$ of GDP) than it would have been if these variables were at the average values of the non-CFA countries. From the mid-1980s until the CFA devaluation in 1994, even though inflation was still lower within the CFA than outside, the persistent misalignment of the real exchange rate in the CFA zone at a time when non-CFA countries were rapidly eliminating the most egregious misalignment worked to the CFA's disadvantage, lowering by $0.75 \%$ of GDP the actual revenue yield relative to the counterfactual. With the devaluation of 1994 and the fall in inflation in the non-CFAs the difference between the two groups becomes negligible, although because of still lower average inflation there is a modest gain in favour of the CFA countries.

So far we have maintained the assumption that the behavioural response of the different country groups to their environment, broadly defined, is given. As we noted in the introduction it was suggested that the institutional features of the CFA franc zone contributed to the inflexibility of the regime in response to (common) external changes, most importantly in the equilibrium real exchange rate. To conclude our analysis of the results we therefore consider a third counterfactual in which we assume that the CFA countries responded to movements 
in the equilibrium real exchange rate in the same fashion as occurred in the nonCFA countries. Letting the subscript $R$ denote the equilibrium real exchange rate, this counterfactual is then defined as

$$
\begin{aligned}
\hat{y}_{C}^{C F 3} & =\hat{\beta}_{C} X_{N}+\left(\hat{\beta}_{N R}-\hat{\beta}_{C R}\right) X_{N R} \\
& =\hat{y}_{C}^{C F 1}+\left(\hat{\beta}_{N R}-\hat{\beta}_{C R}\right) X_{N R}
\end{aligned}
$$

In this case there is a significant increase in the counterfactual tax yield, contributing in excess of an additional one percentage point of GDP by the end of the period. In fact, Counterfactual 3 generates a tax yield that is higher than that observed for the non-CFA countries by the very end of the period. ${ }^{16}$

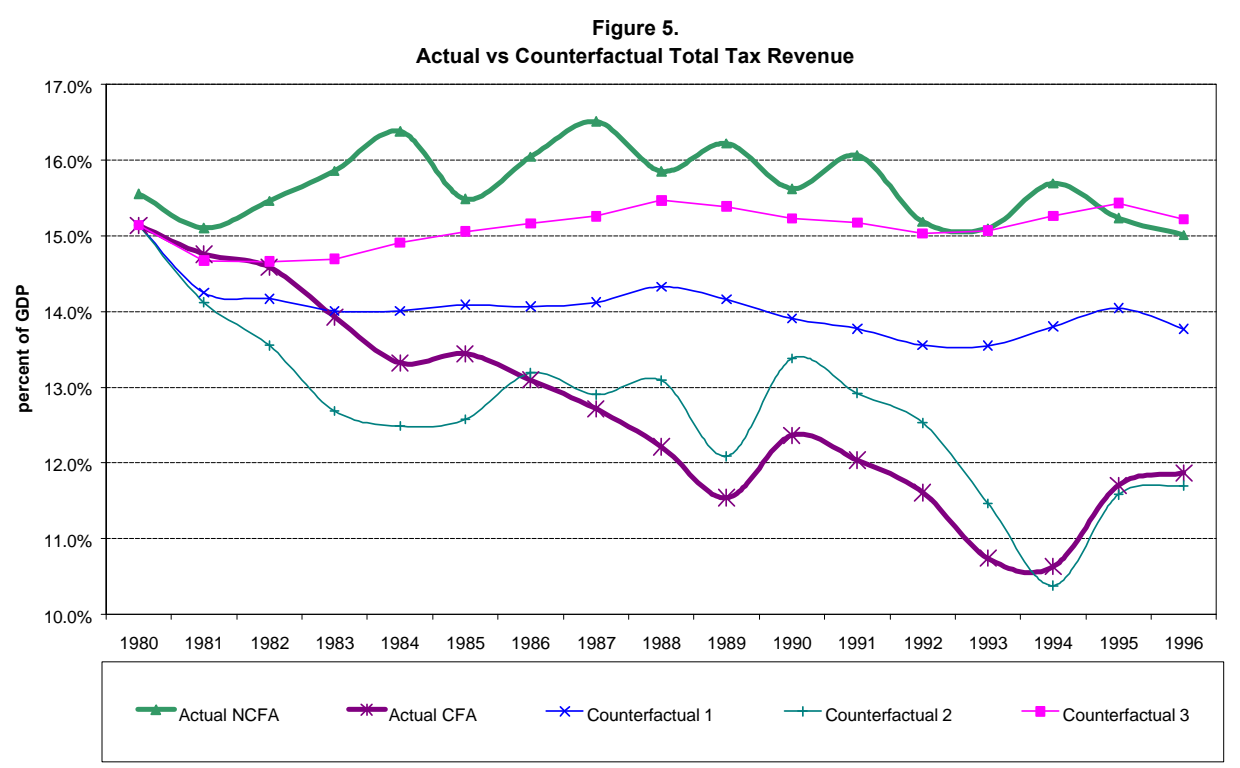

Table 8 repeats this analysis for the individual components of the total tax yield where for convenience we have taken sub-period averages over the full sample. Each row of the table measures the marginal contribution to revenue in the CFA countries as a percentage of GDP under the three counterfactuals, where a positive (negative) value indicates the increase (decrease) relative to the actual outturn that would have been enjoyed by the average CFA economy.

Although these counterfactuals are necessarily crude - not least since we make strong assumptions about the exogeneity of the independent variables including real GDP - three main conclusions emerge from Figure 5 and Table 8. The first is that differences in structure taken crudely account for a large proportion of the difference in revenue performance, given the structure of taxes in the two regions. By the mid-1990s differences in structure accounted for approximately $63 \%$ of the total revenue gap. The second important conclusion is that our results bear out Nashashibi and Bazzoni's (1994) conjecture concerning the behaviour of CFA revenue performance in the late 1980s which motivated

\footnotetext{
${ }^{16}$ This simply reflects the fact that the CFA response to the remaining determinants of total revenue is, in some sense, "more favourable" than that of the non-CFA countries.
} 
this paper. Although there were initial revenue gains from low inflation these were progressively offset by increasing real exchange rate misalignment, which reached a peak in the early 1990s before the devaluation of the CFA Franc. Indeed, over the middle decade of our sample, 1983-92, our second counterfactual suggests that the CFA revenue yield would have been more or less stationary in the absence of differential misalignment and inflation instead of actually falling by around 1.5 percent of GDP. This effect is seen to work most strongly through the effect on trade and indirect taxes which, combined, would have been about 0.5 percent of GDP higher in the late 1980s had the CFA countries been able to limit the growing misalignment. ${ }^{17}$ Over the entire sample period, however, although these policy factors had a poweful effect on the time path of revenue they had no significant impact on the cumulative decline in the total revenue yield. Finally, these results suggest that the differential response to movements in the equilibrium real exchange rate does matter for revenue, adding up to around an additional 1.5 percent of GDP to revenue performance.

Table 8. Counterfactual changes in CFA tax yields.

\begin{tabular}{|c|c|c|c|c|}
\hline \multirow{2}{*}{\multicolumn{2}{|c|}{ Tax }} & $1980-86$ & 1987-93 & 1994-96 \\
\hline & & \multicolumn{3}{|c|}{ [ percent of GDP ] } \\
\hline \multicolumn{5}{|c|}{ Total Taxes } \\
\hline & Structure $[\mathrm{CF} 1]$ & 0.24 & 2.02 & 2.47 \\
\hline & Policy $[\mathrm{CF} 2]$ & -0.75 & 0.74 & -0.18 \\
\hline & ERER $[\mathrm{CF} 3]$ & 0.76 & 1.32 & 1.43 \\
\hline \multicolumn{5}{|c|}{ Income Taxes } \\
\hline & Structure[CF1] & 0.14 & 0.51 & 0.56 \\
\hline & Policy[CF2] & -0.07 & -0.03 & -0.08 \\
\hline & ERER $[\mathrm{CF} 3]$ & -0.06 & -0.09 & -0.09 \\
\hline \multicolumn{5}{|c|}{ Domestic Indirect } \\
\hline & Structure[CF1] & 0.28 & 0.26 & -0.04 \\
\hline & Policy $[\mathrm{CF} 2]$ & -0.28 & 0.25 & -0.14 \\
\hline & ERER $[\mathrm{CF} 3]$ & 0.12 & 0.79 & 0.69 \\
\hline \multicolumn{5}{|c|}{ Trade Taxes } \\
\hline & Structure[CF1] & 0.63 & 1.87 & 1.78 \\
\hline & Policy[CF2] & -0.07 & 0.24 & 0.10 \\
\hline & ERER $[\mathrm{CF} 3]$ & 0.00 & 0.46 & 0.23 \\
\hline
\end{tabular}

The capacity of the arrangements embodied in the CFA Franc zone to deliver consistently reduced inflation relative to other countries in sub-Saharan Africa has featured prominently in discussions of their relative merits for many years. More recently, there has been much interest in their possible role in inducing cumulative distortions, especially misalignment of the real exchange rate. The data presented earlier in this paper demonstrate the continuing truth of the proposition concerning inflation. They also underline two other important differences in performance between the two groups of countries, where by contrast

\footnotetext{
${ }^{17}$ Note that this figure, in fact, understates the pure cost of misalignment since at the time CFA inflation was still lower than in the non-CFA countries.
} 
the non CFA countries have outperformed the CFA ones: they have generated growing as opposed to falling per capita incomes, and they have sustained the share of tax revenues in GDP as opposed to seeing this fall. We have had nothing to say about the first of these outcomes, but have focussed on the second. It has previously been conjectured that the CFA arrangements not only resulted in exchange rate misalignment but that this misalignment had itself caused the revenue decline.

In this paper we have derived estimates of equilibrium real exchange rates and hence of the extent of misalignment, which broadly support the first contention. Specifically, the non CFA countries were able during the 1980s to rectify their initial very high real overvaluation, whereas this increased, albeit from a low initial level, for the CFA countries, up until the devaluation of 1994. Perhaps more importantly, allowing for country specific effects, we found that we could pool across the two types of nominal exchange rate regimes: the way in which the fundamentals determine the equilibrium exchange rate is common to both groups of countries, as theory would suggest. The CFA institutions would then have their differential impact via different inflation, different misalignment and other mechanisms, but not via a shift in the relation between the fundamentals and the equilibrium real exchange rate.

We then proceeded to investigate the second contention concerning the link between the real exchange rate and revenue performance, first in a simple theoretical model, and then econometrically. We examined to what extent the differential - and relatively poor - revenue performance of the CFA countries could be attributed to three different groups of factors. The first comprised differences in structure and in the economic environment experienced by the two groups of countries (and hence inter alia in their equilibrium real exchange rates), the second comprised differences in policy factors associated with the exchange rate regime, such as inflation and misalignment, and the third concerned differences in their revenue responses to changes in the equilibrium real exchange rate. Our conclusion was that structural and environmental factors were very important, explaining well over half the discrepancy, and that during the early 1990s the failure to eliminate exchange rate misalignment contributed a large proportion of this shortfall. Finally, we suggested that differential behavioural responses to the same movements in the equilibrium real exchange rate were also important, accounting for $15-30 \%$ of the discrepancy: these presumably reflect other institutional differences between the CFA countries and the rest, over and above those specific to nominal exchange rate management.

There are of course a multitude of reasons for wishing to minimize both inflation and exchange rate misalignment, and it does seem to be true that CFA-type arrangements involve a trade-off between them. From the narrow but important perspective of revenue productivity, these results suggest that reduced inflation and increased misalignment at the magnitudes associated with the CFA zone can have significant temporary revenue consequences. However the poor cumulative revenue performance of the CFA countries over the entire period appears to result mainly from a different evolution of environmental and structural features and also from the different (institutionally determined) ways in which revenue responds to this evolution. The exchange rate regime itself does not seem to have been of central importance to this cumulative story. 


\section{References}

[1] Adam, C.S., D.L.Bevan, and G.Chambas. "Mobilisation fiscale et regime de change en Afrique Subsaharienne." mimeo, CERDI, Universite d'Auvergne, Clermont-Ferrand, 1998.

[2] Arellano, M., and S.R.Bond. "Dynamic Panel Data Models using DPD." mimeo , Nuffield College, Oxford, 1998.

[3] Baffes, J., I.Elbadawi and S.O'Connell. "Single Equation Estimation of the Real Exchange Rate" in L.Hinkle and P.Montiel (eds) Exchange Rate Misalignment World Bank, 1999.

[4] De Melo, J., and S.Devarajan. "Membership of the CFA Zone: Odyssen Journey or Trojan Horse" in S.Fischer and A.Chhibber (eds) Economic Reform in Sub-Saharan Africa World Bank, 1991.

[5] Dixit,A., and V.Norman. The Theory of International Trade, Cambridge University Press, 1980.

[6] Elbadawi, I. "Estimating Long-Run Equilibrium Real Exchange Rates" in J.Williamson (ed) Estimating Equilibrium Exchange Rates, Institute for International Economics, 1994.

[7] Elbadawi, I. and R.Soto. "Real Exchange Rates and Macroeconomic Adjustment in Sub-Saharan Africa and other Developing Countries" Journal of African Economies, vol 6, 1997.

[8] Ghura, D. "Tax Revenue in Sub-Saharan Africa: Effects of Economic Policies and Corruption" IMF Working Paper 98/135, 1998.

[9] Leuthold, J. "Tax Shares in Developing Economies: A Panel Study" Journal of Development Economics, vol 35, 1991.

[10] Nashashibi, K., and Bazzoni, S. "Exchange Rate Strategies and Fiscal Performance in Sub-Saharan Africa", IMF Staff Papers, March 1994.

[11] Pesaran, H., and R.Smith. "Estimating Long-Run Relationships from dynamic heterogeneous panels." Journal of Econometrics, vol 68, 1995.

\section{Appendix}

Equations $(6,7$, and 9$)$ define the macroeconomic balance, non-tradable equilibrium, and the public sector balance respectively. Totally differentiating these three expressions we derive the following system

$$
\begin{gathered}
{\left[\begin{array}{c}
d Q \\
d u \\
d U
\end{array}\right]=\left[\begin{array}{ccc}
0 & e_{u} & E_{u} \\
\left(e_{Q}-\tau_{1}\left(R_{Q}+Q R_{Q Q}\right)-\tau_{2} T(1-\phi) R_{T}\right) & e_{u} & E_{Q U} \\
\left(e_{Q Q}+E_{Q Q}-R_{Q Q}\right) & 0
\end{array}\right]^{-1}} \\
{\left[\begin{array}{ccc}
1 & (1-\phi) R_{T} & 0 \\
0 & (1-\phi) R_{T Q} & 0 \\
\phi(1-\gamma(\pi)) & \tau_{1} Q R_{Q T}+\tau_{2}(1-\phi)\left(R_{T}+T R_{T T}\right) & \Psi
\end{array}\right]\left[\begin{array}{c}
d A \\
d T \\
d \pi
\end{array}\right]}
\end{gathered}
$$


where $\Psi=-\left[d \beta_{\pi}+t \alpha_{\pi}\left(1+T(1-\phi) R_{T}\right)+\phi \gamma_{\pi}\left(T(1-\phi) R_{T}+A\right)\right]$. Letting the determinant of the inverse matrix be

$$
\begin{aligned}
\Delta= & -\left[E_{U} e_{u}\left(e_{Q Q}+E_{Q Q}-R_{Q Q}\right)\right. \\
& +\left(E_{U} e_{Q u}-e_{u} E_{Q U}\right)\left(\tau_{1}\left(R_{Q}+Q R_{Q Q}\right)+\tau_{2} T(1-\phi) R_{T}-e_{Q}\right)
\end{aligned}
$$

we solve for the RER as

$$
\begin{aligned}
d Q= & \frac{1}{\Delta}\left[\left\{e_{u} E_{Q U}-\left(e_{u} E_{Q U}-E_{U} e_{Q u}\right) \phi(1-\gamma(\pi))\right\} d A\right. \\
& +\left\{e_{u} E_{Q U}(1-\phi) R_{T}-E_{u} e_{u}(1-\phi) R_{T Q}\right. \\
& -\left(e_{u} E_{Q U}-E_{U} e_{Q u}\right)\left(\tau_{1} Q R_{Q T}+\tau_{2}(1-\phi)\left(R_{T}+T R_{T T}\right)\right\} d T \\
& \left.-\left\{\left(e_{u} E_{Q U}-E_{U} e_{Q u}\right) \Psi\right\} d \pi\right] .
\end{aligned}
$$

Defining $d_{y}=e_{Q u} / e_{u}$ and $D_{y}=E_{Q u} / E_{U}$ we re-write $\Delta$ as

$$
\begin{aligned}
\Delta= & -\frac{1}{E_{U} e_{u}}\left[\left(\tau_{1}\left(R_{Q}+Q R_{Q Q}\right)\right.\right. \\
& \left.+\tau_{2} T(1-\phi) R_{T}-e_{Q}\right)\left(d_{y}-D_{y}\right)+\left(\left(e_{Q Q}+E_{Q Q}-R_{Q Q}\right)\right] .
\end{aligned}
$$

Using this expression (A2) simplifies directly to (14).

\subsection{Data appendix}

Data on revenue components are from IMF staff estimates made available to the authors and from the IMF "Government Financial Statistics" (various issues). Revenue categories correspond to the standard GFS classifications as follows: $y \operatorname{tax}=$ lines $1+2+3+4 ;$ itax $=$ line $5 ;$ ttax $=$ line $6 ;$ ntax $=$ lines $7+8+9+12$; txrev $=$ ytax + itax + ttax; trev $=$ ttax + ntax. Data on nominal exchange rates and domestic and world prices were collected from IMF "International Financial Statistics" (lines rh , 64, and USA line 63 respectively). Data on income, the structure of production and consumption, world import and export prices and the terms of trade were collected from the World Bank WDI data base. Aid flows and interest payments are from World Debt Tables. The data used in the econometric analysis are as follows:

lrer (log) actual real exchange rate (using official exchange rate)

lerer (log) equilibrium real exchange rate

mis misalignment index (higher values denote less misalignment

infl annual inflation

lga $\quad(\log )$ aid flows net of amortization

lin $(\log )$ interest payments on official debt

naid (log) net transfers on aid (lga-lin)

ag-y agricultural share in GDP

ind_y industry (incl mining) share in GDP

lop $(\log )$ openness: trade as a share of GDP

lypc $\quad(\log )$ real per capita income

ltot $(\log )$ terms of trade

lpm (log) import price index

lpx $\quad(\log )$ export price index

lgy (log) government consumption 
The Country classification is as follows:

1. CFA. This group combines members of the BCEAO and BEAC maintaining a fixed nominal exchange rate with the French Franc ( Benin ; Burkina Faso; Central African Republic; Cote d'Ivoire ; Mali; Niger; Senegal ; Togo).

2. Non-CFA. This group consists of countries predominantly from Anglophone Africa. In many cases the countries adopted a unilateral fixed exchange rate regime, usually with the US dollar, throughout some or all of the period (Burundi; The Gambia; Ghana; Kenya; Madagascar; Mauritania; Malawi; Mauritius; Rwanda; Sierre Leone; Tanzania; Uganda; Zambia; Zimbabwe).

3. Countries excluded from the sample: (i) countries whose tax base is dominated by natural resources, mainly oil producing countries - Gabon, Cameroon, Congo, Nigeria, Botswana; (ii) countries for which there were insufficient or dubious data over the sample period - Namibia, Swaziland, Lesotho, Mozambique, Angola, Zaire, Reunion, Comoros, Seychelles, Ethiopia, Sudan, Sao Tome \& Principe, Liberia, Guinea, Guinea-Bissau, Cape Verde; (iii) South Africa. 